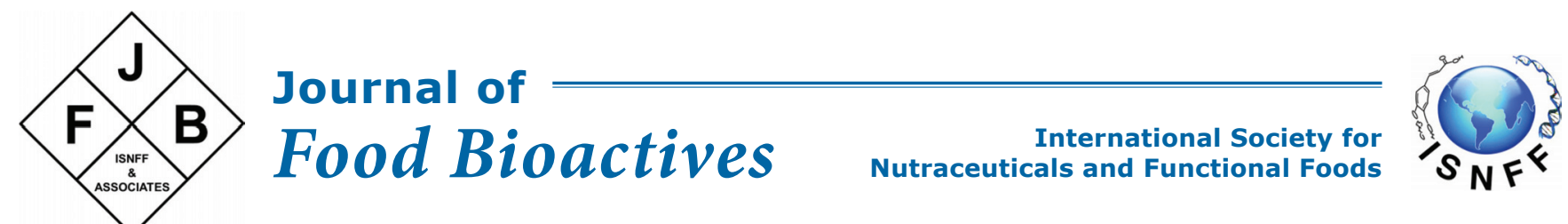

\title{
Functional fermented carob milk: probiotic viability and polyphenolic profile
}

\author{
Yasmina Ait Chait ${ }^{\mathrm{a}, \mathrm{b}}$, Aynur Gunenc ${ }^{\mathrm{b}}$, Farida Bendalia and Farah Hosseinian ${ }^{\mathrm{b}, \mathrm{c}^{*}}$ \\ a'Laboratoire de Microbiologie Appliquée, Faculté des Sciences de la Nature et de la Vie, Université de Bejaia, Bejaia 06000, Algeria \\ ${ }^{b}$ Food Science and Nutrition, Chemistry Department, 1125 Colonel By Drive, Carleton University, Ottawa, Ontario, K1S 5B6, Canada \\ 'Institute of Biochemistry, 1125 Colonel By Drive, Ottawa, Ontario, K1S 5B6, Canada \\ *Corresponding author: Farah Hosseinian, Food Science and Nutrition, Chemistry Department, 1125 Colonel By Drive, Carleton Univer- \\ sity, Ottawa, Ontario, K1S 5B6, Canada. Tel: 1-613-520-2600 x 2840; E-mail: FarahHosseinian@cunet.carleton.ca \\ DOI: $10.31665 /$ JFB.2021.14273
}

Received: June 25, 2021; Revised received \& accepted: June 30, 2021

Citation: Chait, Y.A., Gunenc, A., Bendali, F., and Hosseinian, F. (2021). Functional fermented carob milk: Probiotic viability and polyphenolic profile. J. Food Bioact. 14: 114-125.

\begin{abstract}
This study aimed to develop a synbiotic fermented milk with $4 \%$ carob powder (CB) as a functional ingredient and using Lactobacillus brevis as a new isolated probiotics strain. Physicochemical characteristics, probiotic viability, total phenolic content (TPC) and antioxidant capacity, antibacterial activity as well as the hypoglycemia activity of carob fermented milk were measured during a cold storage and gastro-intestinal digestion. CB addition to fermented milk improved the growth of Lactobacillus brevis and maintained their viability during the storage period (8 log CFU/g) and after digestion (7 log CFU/g). Carob fermented milk displayed higher TPC and higher antioxidant capacity during the storage. The digestion resulted in the release of bioaccessible phenolics where gallic acid $(441 \%)$ and $(+)$-catechin (486\%) were the most quantified phenolic compounds; thus, the inhibition of $\alpha$-amylase (52\%), $\alpha$-glucosidase (37\%) activity and higher antibacterial potential. These results demonstrate the potentials of carob fermented milk to be an important source of viable probiotics and bioaccessible polyphenols.
\end{abstract}

Keywords: Synbiotic fermented milk; Carob; Probiotic; Polyphenols; Bioaccessibility.

\section{Introduction}

Development of functional foods, in which probiotic, and synbiotic dairy products constitute an important class; with health promoting natural ingredients have been growing constantly within the last decade (Granato et al., 2018). Fermented milks are the most frequently used food based vehicle to deliver probiotic bacteria as well as prebiotics worldwide, with high consumer preference (Annunziata and Vecchio, 2013). Probiotics are living microorganisms that are safe for human consumption and, when ingested in sufficient amounts, result in beneficial effects on human health (Hill et al., 2014). Prebiotics, on other hand, are non-digestible compounds that through metabolization by microorganisms residing in colon modulate gut microbiome composition or activity conferring beneficial physiological effects on the host (Gibson et al., 2017). There is an evident potential for a synbiotic effect of probiotics and prebiotics since the latter promote the growth of the former one. Synbiotics are defined as "a combination of probiotics and prebiotics that beneficially affects the host by improving the survival and implementation of live microbial dietary supplements in the gastro-intestinal (GI) tract" (Mohanty et al., 2018). The combination of prebiotics and probiotics in a single product give additive benefits compared to their use individually (de Vrese and Schrezenmeir, 2008). Inulin, fructo-oligosaccharides and galacto-oligosaccharides are prebiotics with proven ability to increase the growth and the counts of probiotic strains (Balthazar et al., 2017). There is great economic interest in finding other prebiotic-rich food matrices. Carob (Ceratonia silique L.) is a natural sweetener and may be used as a nutritious substitute for cocoa powder (Durazzo et al., 2014). It was 
reported that carob pulp consumption could lead to a beneficial effect on diabetes symptoms prevention, hyperlipidemia control, diarrheal symptoms reduction, and anti-proliferative and apoptotic activities against cancer cells. Several studies have attributed these health benefits to the phenolic fraction of carob pulp and its richness on dietary fibres (Loullis and Pinakoulaki, 2018). Carob phenolics belong mainly to the groups of phenolic acids, flavonoids and tannins and can be found in free, bound or soluble conjugated forms and they are potent source of antioxidants (Chait et al., 2020)). Thus, addition of carob polyphenols to fermented milks may improve the antioxidant activity of this latter. On the other hand, survival of probiotic bacteria in such supplemented fermented milk during its shelf life, in addition to their survival and changes in polyphenols content, in GI tract upon consumption, may be affected.

Thus, the aim of the current study was; 1) to evaluate effects of carob powder addition on physicochemical characteristics and viability of probiotic bacteria (Lactobacillus brevis) in fermented milk during refrigerated storage and simulated gastrointestinal digestion, and 2) to assess the bioaccessibility of phenolic compounds and 3 ) to investigate the antioxidant activity (DPPH and ORAC) and hypoglycemia activity ( $\alpha$-amylase and $\alpha$-glucosidase inhibition) during simulated gastro-intestinal digestion of the carob fortified fermented milk.

\section{Material and methods}

\subsection{Chemicals}

Human saliva $\alpha$-amylase (14 $\mu$ kat $/ \mathrm{mg}$ proteins), pepsin from porcine gastric $(11 \mu \mathrm{kat} / \mathrm{mg})$, pancreatin from porcin pancreas (4xUPS, $0.12 \mu \mathrm{kat}$ of trypsin/mg), $\alpha$-amylase from Bacillus licheniformis, $\alpha$-glucosidase and bile salts were purchased from Sigma-Aldrich (St. Louis, Missouri, USA). Solvents including acetone, methanol, acetic acid and acetonitrile were analytical grade and purchased from Sigma-Aldrich. Folin-ciocalteau reagent, sodium carbonate, 2,2-dipheny-1-picryhydrazyl radical (DPPH), fluorescein, trolox (6-hydroxy-2,5,7,8-tetramethylchroman-2-carboxylic acid), 2,2-azobis (2-methylpropionamidine) dihydrochloride $(\mathrm{AAPH})$, potassium persulfate, DNS (3,5-dinitrosalicylic acid), p-nitrophenyl- $\alpha$-D-glucopyranoside and sodium hydroxide $(\mathrm{NaOH})$ were obtained from Sigma-Aldrich (Oakville, ON, Canada). The phenolic acid standards (over $\geq 980 \mathrm{~g} / \mathrm{Kg}$ pure); gallic, protocatechic, chlorogenic, caffeic, vanillic, syringic, $p$-coumaric, ferulic, $O$-coumaric, trans-cinnamic, the flavanoid standards; $(+)$-catechin, rutin, isoquercitrin, myricetin, apigenin and kaempherol were also purchased from Sigma-Aldrich (St. Louis, Missouri, USA). De Man, Rogosa and Sharp (MRS), M17 and lactose used to growth the bacterial strains were purchased from (Sigma Aldrich, Canada).

\subsection{Carob powder preparation}

Carob pods (Ceratonia siliqua L.) used in this study were collected during July-August 2016 in Bejaia city (Algeria) and were in total maturity stage (ripe). All carob pods were washed with distilled water and seeds were removed. The pulps were dried in microwave (Hotpoint Ariston, USA) at $720 \mathrm{~W}$ for $15 \mathrm{~min}$, ground to a fine powder using a commercial food blender and passed through a $0.149 \mathrm{~mm}$ sieve to obtain uniformly sized powder. The powder was then sterilized under UV irradiation for $30 \mathrm{~min}$.

\subsection{Fermented milk}

\subsubsection{Milk preparation and bacterial cultures}

The skim milk (SM) was prepared by dissolving no-fat powder milk (great value, Ottawa, Canada) in warm distilled water (37 $\left.{ }^{\circ} \mathrm{C}\right)$, leading to reconstituted milk with about $13 \%$ (w/v) solid content. SM base was thermally sterilized at $90{ }^{\circ} \mathrm{C}$ for $10 \mathrm{~min}$ in a water bath and stored at $4{ }^{\circ} \mathrm{C}$ for $24 \mathrm{~h}$. Lactococcus (Lc.) lactis C15 (starter culture), Lactobacillus (Lb.) brevis B13 and B38 (probiotic cultures) strains used in this study were previously isolated from Algerian artisanal cheeses (Ait Chait et al., 2021). These strains were selected based on their technological and probiotic properties, as well as their ability to grow in the presence of carob powder. All strains were phenotypically and genotypically identified by DNAr $16 \mathrm{~S}$ sequencing (McGill University and Génome Québec Innovation Centre). For preparation of inoculums, the three strains were activated by two successive culture transfers in de Man, Rogosa and Sharp (MRS) or M17 broth (Sigma Aldrich, Canada) at $30^{\circ} \mathrm{C}$ for $18 \mathrm{~h}$, then in sterilized reconstituted skim milk (SM) $\left(30^{\circ} \mathrm{C}\right.$ for $\left.18 \mathrm{~h}\right)$.

\subsubsection{Fermentation process and storage}

Prior fermentation, three batches of SM were prepared and warmed to $30{ }^{\circ} \mathrm{C}$. The first two batches were fortified separately with $4 \%(\mathrm{w} / \mathrm{v})$ of carob powder or inulin (the best concentration of carob powder to be added to the fermented milks without resulting in syneresis was preliminary determined as 4\% [Data not shown]. The third batch was used as control without any prebiotic supplementation. Then, Lc. lactis strain $\mathrm{C} 15$ was added at $1 \%(\mathrm{v} / \mathrm{v})$ corresponding to $10^{7} \mathrm{CFU} / \mathrm{mL}$ to the three batches. Each batch was then divided into four equal portions, which were inoculated with $1 \%(\mathrm{v} / \mathrm{v})$ corresponding to $10^{5} \mathrm{CFU} / \mathrm{mL}$ of each Lb. brevis probiotic strain (B13 or B38) separately or in mixture as summarized in Table 1. All fermented milks were incubated at $30{ }^{\circ} \mathrm{C}$ for $16 \mathrm{~h}$ and then stored at $4{ }^{\circ} \mathrm{C}$ for 28 days. The products were analyzed after fermentation and on the $1^{\text {st }}, 7^{\text {th }}, 14^{\text {th }}, 21^{\text {st }}$ and $28^{\text {th }}$ day of storage for microbiological and physicochemical characteristics.

\subsection{Microbiological analysis}

Starter and probiotic strains viability were determined in all samples, just after fermentation and during storage using the pour plate technique. Hence, $1 \mathrm{~mL}$ aliquot samples were removed and subjected to appropriate serial dilutions in $0.1 \%(\mathrm{w} / \mathrm{v})$ peptone water. Lc. lactis $\mathrm{C} 15$ enumeration was performed in M17 agar supplemented with $0.1 \%(\mathrm{w} / \mathrm{v})$ lactose and Lb. brevis B13 and $\mathrm{B} 38$ counts were determined in MRS agar $(\mathrm{pH}=5.4)$. The plates were then incubated at $30{ }^{\circ} \mathrm{C}$ for $48 \mathrm{~h}$ under aerobic conditions.

\subsection{Physicochemical characterization}

The $\mathrm{pH}$ of various samples was measured directly with a $\mathrm{pH}$ meter (Orion 2 star $\mathrm{pH}$ benchtop, Thermo scientific, USA). The titrable acidity (TA) was determined and expressed as g of lactic acid per $100 \mathrm{~g}$ of fermented milk. The viscosity of each sample was measured using a Brookfield viscosimeter (model DV-E, MA, USA). According to the microbial and physicochemical analysis 
Table 1. Experimental design for carob powder addition in fermented milks

\begin{tabular}{lll}
\hline Formulation & Prebiotic & Sample coding \\
\hline $\mathrm{SM}+$ Lc. lactis C15 & 0 & $\mathrm{~F}$ \\
$\mathrm{~F}+$ Lb. brevis B13 & 0 & $\mathrm{FP1}$ \\
$\mathrm{F}+$ Lb. brevis B38 & 0 & $\mathrm{FP} 2$ \\
$\mathrm{~F}+$ Lb. brevis B13 + Lb. brevis B38 & 0 & $\mathrm{FP} 12$ \\
$\mathrm{SM}+$ Lc. lactis C15 & $\mathrm{C}$ & $\mathrm{FC}$ \\
$\mathrm{F}+$ Lb. brevis B13 & $\mathrm{C}$ & $\mathrm{FCP1}$ \\
$\mathrm{F}+$ Lb. brevis B38 & $\mathrm{C}$ & $\mathrm{FCP} 2$ \\
$\mathrm{~F}+$ Lb. brevis B13 + Lb. brevis B38 & $\mathrm{C}$ & $\mathrm{FCP12}$ \\
$\mathrm{SM}+$ Lc. lactis C15 & I & $\mathrm{FI}$ \\
$\mathrm{F}+$ Lb. brevis B13 & I & FIP1 \\
$\mathrm{F}+$ Lb. brevis B38 & I & FIP2 \\
$\mathrm{F}+$ Lb. brevis B13 + Lb. brevis B38 & I & FIP12 \\
\hline
\end{tabular}

SM: skim milk, F: fermented milk with only yogurt starter cultures, C: carob powder I: inulin, FC: fermented milk with carob powder, FI: fermented milk with Inulin, P1 probiotic 1 (Lb. brevis B13), P2: probiotic 2 (Lb. brevis B38), P12: P1 + P2. First column represents the recipe of 4 different treatments for each row; control group (top row), Carob powder added milk (middle row) and inulin added milk (last row). The second column represents what type of prebiotic addition to the formulations; " 0 " means no addition, " $\mathrm{C}$ " means carob powder addition, and "I" means inulin addition. The third column represents the coding for 4 different treatments for each sample group in 3 rows.

of fermented milks supplemented with carob powder, the formulation showing the best microbial growth of probiotic strains and best physicochemical parameters was chosen to continue following studies. Total phenolic contents (TPC), HPLC and antioxidant capacity analysis were performed for the selected formulation before and during the storage process and the in-vitro gastrointestinal digestion.

\subsection{Total phenolic contents (TPC)}

TPC of fermented milks was spectrophotometrically determined using the modified procedure of the folin-ciocalteu adapted to 96well plate assay, as described by Gao et al. (2002). The absorbance was read at $725 \mathrm{~nm}$ using a microplate reader (Epoch, Biotek, USA) and expressed as $\mathrm{mg}$ of gallic acid equivalent per $\mathrm{g}$ of sample (mg GAE/g).

\section{7. $H P L C$}

Phenolic composition analysis was forms were performed for the selected fermented milk using a reverse-phase (RP)-HPLC (Waters Corp., Fisher Scientific, Milford, USA) according to (Gunenc et al., 2015). Chromatographic separation was carried out by a RP Atlantis R T3 column $(150 \mathrm{~mm} \times 4.6 \mathrm{~mm}, 5 \mu \mathrm{m}$ particle size; Waters, Milford, MA) using two solvents system: (A) $0.5 \%(\mathrm{v} / \mathrm{v})$ formic acid in milliQ water and (B) $100 \%$ acetonitrile, under the following conditions: $0 \mathrm{~min}, 95 \% \mathrm{~A} ; 0-35 \mathrm{~min}, 50 \% \mathrm{~A} ; 35-40 \mathrm{~min}, 90 \%$ $\mathrm{A}$ and then return to $95 \% \mathrm{~A}$ in $10 \mathrm{~min}$. The chromatograms were recorded at 280 and $320 \mathrm{~nm}$ for phenolic acids and flavonoids, respectively. The identification of the phenolic compounds was obtained by comparing the retention times with available external standards injected in the same conditions. Their quantification was carried out through calibration curves of the standards.

\subsection{Antioxidant capacity}

\subsubsection{DPPH scavenging activity}

The antiradical ability of the selected fermented milk was measured by DPPH (1,1-diphenyl-2-picrylhydrazyl) assay according to the method of (Brand-Williams et al., 1995).The results were expressed as $\mathrm{mg}$ gallic acid equivalent per gram of sample $(\mathrm{mg}$ GAE/g) after reading the absorbance at $519 \mathrm{~nm}$ after $30 \mathrm{~min}$ of incubation.

\subsubsection{Oxygen radical absorbance capacity (ORAC)}

The antioxidant capacity of the selected fermented milks was also performed using an oxygen radical absorbance capacity (ORAC) assay using a fluorescence plate reader following the procedure of(Huang et al., 2002). ORAC values of all samples were calculated using the differences of areas under the fluorescence decay curves between the blank and a sample. The results were expressed as micromole Trolox equivalents per gram of sample ( $\mu \mathrm{mol} \mathrm{TE} / \mathrm{g})$.

\subsection{In vitro simulated gastrointestinal digestion}

The selected formulation of fermented milk (FCP12) was subjected to an in vitro simulated gastrointestinal digestion to determine the effect of digestion on its phenolic content and its antioxidant capacity as well as on the starter and probiotic strains viability. For this, $10 \mathrm{~g}$ of fermented milk was digested following the model reported by (Minekus et al., 2014), which is based on three sequential steps: salivary, gastric and intestinal digestion. Simulated fluids (salivary, gastric and intestinal) and enzymes solutions were prepared at the same molarity as reported in the method. Aliquots were collected at the end of each phase (oral, gastric and intestinal) and placed in an ice bath for $10 \mathrm{~min}$ to deactivate the enzymes. Then, samples were freeze-dried and stored at $-20{ }^{\circ} \mathrm{C}$ until further analysis. Regarding the enumeration of starter and probiotics strains, aliquots were plated on appropriate media as described in section 2.3

\subsection{Bioaccessibility index}

The Bioaccessibility index of phenolic compounds released from the fermented milk after digestion was calculated as follows:

$$
\text { Bioaccessibility index }(\%)=(\mathrm{A} / \mathrm{B}) \times 100
$$

Where: $\mathrm{A}$ is the content $(\mu \mathrm{g})$ of individual phenolic compounds quantified by HPLC after the in vitro digestion of the fermented milk and B is the content $(\mu \mathrm{g})$ of phenolic compounds quantified in fermented milk before the in vitro digestion.

\subsection{Antibacterial activity of fermented milk}

Fermented milk (FCP12) samples were centrifuged at $14,000 \times \mathrm{g}$ at room temperature for $10 \mathrm{~min}$ and the supernatant was used to measure the antibacterial activity using Escherichia coli ATCC 25922, 
Table 2. Probiotic Lb. brevis (P1 and P2) viable counts $(\log \mathrm{CFU} / \mathrm{mL})$ in fermented milks during storage period $\left(4^{\circ} \mathrm{C}\right)^{*}$

\begin{tabular}{lllllll}
\hline Fermented milks & Day 0 & Day 1 & Day 7 & Day 14 & Day 21 & Day 28 \\
\hline FP1 & $6.43 \pm 0.11^{\mathrm{aA}}$ & $6.42 \pm 0.09^{\mathrm{aA}}$ & $6.35 \pm 0.08^{\mathrm{abA}}$ & $6.28 \pm 0.09^{\mathrm{bA}}$ & $6.17 \pm 0.04^{\mathrm{cA}}$ & $6.04 \pm 0.25^{\mathrm{dA}}$ \\
FP2 & $6.39 \pm 0.09^{\mathrm{aA}}$ & $6.40 \pm 0.10^{\mathrm{aA}}$ & $6.38 \pm 0.12^{\mathrm{aA}}$ & $6.21 \pm 0.10^{\mathrm{bA}}$ & $6.01 \pm 0.04^{\mathrm{cA}}$ & $5.92 \pm 0.05^{\mathrm{cA}}$ \\
FP12 & $6.28 \pm 0.12^{\mathrm{aA}}$ & $6.26 \pm 0.08^{\mathrm{aA}}$ & $6.11 \pm 0.25^{\mathrm{bA}}$ & $6.05 \pm 0.04^{\mathrm{bA}}$ & $5.82 \pm 0.13^{\mathrm{cA}}$ & $5.74 \pm 0.12^{\mathrm{cA}}$ \\
FCP1 & $8.68 \pm 0.12^{\mathrm{aB}}$ & $8.69 \pm 0.10^{\mathrm{aB}}$ & $8.80 \pm 0.13^{\mathrm{bB}}$ & $8.79 \pm 0.04^{\mathrm{bB}}$ & $8.69 \pm 0.09^{\mathrm{bB}}$ & $8.28 \pm 0.09^{\mathrm{cB}}$ \\
FCP2 & $8.61 \pm 0.18^{\mathrm{aB}}$ & $8.60 \pm 0.09^{\mathrm{aB}}$ & $8.79 \pm 0.08^{\mathrm{bB}}$ & $8.81 \pm 0.11^{\mathrm{bB}}$ & $8.70 \pm 0.09^{\mathrm{bB}}$ & $8.26 \pm 0.14^{\mathrm{cB}}$ \\
FCP12 & $8.66 \pm 0.11^{\mathrm{aB}}$ & $8.65 \pm 0.05^{\mathrm{aB}}$ & $8.98 \pm 0.08^{\mathrm{bB}}$ & $8.93 \pm 0.12^{\mathrm{bB}}$ & $8.89 \pm 0.25^{\mathrm{bB}}$ & $8.58 \pm 0.21^{\mathrm{cB}}$ \\
FIP1 & $7.67 \pm 0.05^{\mathrm{aC}}$ & $7.65 \pm 0.05^{\mathrm{aC}}$ & $7.57 \pm 0.09^{\mathrm{aC}}$ & $7.41 \pm 0.05^{\mathrm{abC}}$ & $7.30 \pm 0.25^{\mathrm{bC}}$ & $7.27 \pm 0.07^{\mathrm{bC}}$ \\
FIP2 & $7.69 \pm 0.18^{\mathrm{aC}}$ & $7.70 \pm 0.11^{\mathrm{aC}}$ & $7.64 \pm 0.12^{\mathrm{aC}}$ & $7.47 \pm 0.12^{\mathrm{bC}}$ & $7.26 \pm 0.07^{\mathrm{cC}}$ & $6.81 \pm 0.14^{\mathrm{dC}}$ \\
FP12 & $7.61 \pm 0.08^{\mathrm{aC}}$ & $7.60 \pm 0.11^{\mathrm{aC}}$ & $7.53 \pm 0.21^{\mathrm{aC}}$ & $7.46 \pm 0.13^{\mathrm{aC}}$ & $6.82 \pm 0.15^{\mathrm{bC}}$ & $6.43 \pm 0.05^{\mathrm{cC}}$ \\
\hline
\end{tabular}

*Values expressed in log CFU/mL as mean \pm standard deviation $(n=3) . A, B, C$ Different capital letters in a column indicates significant differences between fermented milk supplemented with different prebiotics $(P<0.05)$; a,b,c,d Different lowercase letters in a row for each fermented milk denote significant differences during storage period $(P<0.05)$. F: fermented milk without prebiotic addition including P1/P2, FC: fermented milk with carob powder including P1/P2, FI: fermented milk with inulin powder including P1/P2.

Staphylococcus aureus ATCC 25923, Listeria monocytogenes (ATCC 19115) and Salmonella typhimurium (ATCC 14028) as indicator strains. The antibacterial activity of milks samples was measured using the agar-well diffusion method (Hammami et al., 2009). Briefly, nutrient media containing $7.5 \mathrm{~g}$ agar/L was cooled to $45^{\circ} \mathrm{C}$, seeded with an overnight culture of each indicator strain at $1 \%(\mathrm{v} / \mathrm{v})$ and poured into a sterile Petri dish $(25 \mathrm{~mL})$. After solidification, $7 \mathrm{~mm}$ diameter wells were made using the wide end of a sterile glass pipette and filed with $80 \mu \mathrm{L}$ of milk sample supernatants. The plates were kept for $2 \mathrm{~h}$ at $4{ }^{\circ} \mathrm{C}$ before being incubated at $37^{\circ} \mathrm{C}$ for $24 \mathrm{~h}$. After incubation, the diameter of the clear zones was measured using a ruler (the minimum resolution was $1 \mathrm{~mm}$ ) and the results are expressed in $\mathrm{mm}$.

\subsection{2. $\alpha$-Amylase inhibition}

The $\alpha$-amylase inhibition assay of the selected fermented milk was adapted from (Telagari and Hullatti, 2015) with some modifications. Absorbance (Abs) was read at $540 \mathrm{~nm}$ in an Epoch microplate reader (Biotek, USA) and percentage of inhibition was calculated relatively to the negative control having $100 \%$ enzyme activity as follows:

$$
\text { Inhibitory activity }(\%)=\underset{\times 100 .}{\left[\left(\mathrm{Abs}_{\text {sample }}-\mathrm{Abs}_{\text {control }}\right) / \mathrm{Abs}_{\text {control }}\right]}
$$

\subsection{3. $\alpha$-glucosidase inhibition}

The $\alpha$-glucosidase inhibition assay was conducted according to the method of (Yao et al., 2010). The $\alpha$-glucosidase inhibitory activity was calculated as follows:

$$
\% \text { inhibition }=\left[\left(\mathrm{Abs}_{\text {control }}-\mathrm{Abs}_{\text {sample }}\right) / \mathrm{Abs}_{\text {control }}\right] \times 100 .
$$

\subsection{Statistical analyses}

All statistical analyses were carried using IBM's SPSS Statistic version 24 software. Data were expressed as the mean \pm standard deviation (SD) of triplicate experiments. One way analysis of variance (ANOVA) was applied for each parameter followed up with Tukey's post-hoc test for detecting significantly different means $(\mathrm{p}<0.05)$.

\section{Results and discussion}

\subsection{Viable cell counts of starter and probiotic strains}

As the viability of probiotic organisms is considered a key parameter for developing probiotic foods, the viable cell counts of starter and probiotic strains were evaluated after fermentation and their stability were monitored over 28-days storage as illustrated in Table 2. Lc. lactis $\mathrm{C} 15$ population remained relatively stable (values ranged between 9.41 and $9.77 \log \mathrm{CFU} / \mathrm{g}$ ) in all fermented milk formulations, after fermentation and throughout the storage. This strain was not affected $(p>0.05)$ by probiotic co-culture and the presence of prebiotics (inulin or carob powder) over storage period (data not shown). After $16 \mathrm{~h}$ of fermentation, the milks enriched with carob powder $(\mathrm{FC})$ showed significantly $(\mathrm{p}<0.05)$ higher counts of probiotics lactobacilli (B13 and B38) (8 log $\mathrm{CFU} / \mathrm{g}$ ) than the control (F) and inulin enriched-fermented milk (FI) as presented in the Table 2. During the cold storage of the fermented milks, carob powder improved and increased the viability of the lactobacilli strains in the early stage of storage (D7), after that they remained relatively stable up to D21 (Table 2). In D28, the count of both strains decreased by about $0.5 \log \mathrm{CFU} / \mathrm{g}$ in the individual cultures (FCP1 and FCP2) as well as in their co-cultures (FCP12). In addition, Lb. brevis B13 and B38 demonstrated better survival $(\mathrm{p}<0.05)$ under refrigeration storage in the presence of each other (co-culture), probably due to synergistic effects of each probiotic. Even though the decrease in lactobacilli number at the end of storage, the minimum dose recommended by the scientific community to confer potential health benefits $\left(10^{6} \mathrm{CFU} / \mathrm{g}\right.$ of food) (Vasiljevic and Shah, 2008) was maintained in carob fermented milk through its shelf-life. These findings point out an in vitro synbiotic effect of carob powder upon the probiotic strains, which was in accordance with several authors reports, who tested different prebiotic matrices in fermented milks such as lentil, onion juice and green banana flour (Agil et al., 2013; Batista et al., 2017; Li et al., 2016). According to the obtained results, it seems that the constituents of carob powder favored the Lb. brevis B13 and B38 growth. It was already reported that carob pulp contains high level of dietary fibers (Ortega et al., 2011) which was demonstrated to have a prebiotic effect on lactic acid bacteria (LAB) viability (Carlson et al., 2018). The carob dietary fibers may protect the probiotic strains and serve as a carbon source for their 
survival during storage. Other studies have also reported the presence of substantial amounts of polyphenols (Owen et al., 2003) in carob pulp that may have a positive effect on probiotics growth in milk. De Souza et al. (2018) reported that the addition of grape pomace extracts (rich on polyphenolic compounds) to fermented skim milk promoted the growth of Lb. acidophilus (de Souza de Azevedo et al., 2018). Also, the supplementation of cow's milk with phenolic compounds extracted from olive vegetable water increased the growth of LAB by $2.5 \log \mathrm{CFU} / \mathrm{mL}$ (Servili et al., 2011). In addition, the carob polyphenols are important antioxidant factors (Chait et al., 2020), which might scavenge hydrogen peroxide and protect probiotic strains during the fermentation and storage.

\subsection{Physicochemical characterization of fermented milks}

Changes in $\mathrm{pH}$, titrable acidity (TA) and viscosity of different fermented milks during storage period at $4{ }^{\circ} \mathrm{C}$ were presented in Table 3. The addition of $4 \%(\mathrm{w} / \mathrm{v})$ of carob powder promoted $(\mathrm{p}<0.05)$ acids production of in the milks during fermentation comparatively to both control and milk containing inulin. Thus, the $\mathrm{pH}$ values of the skim milk $(\mathrm{SM})(\mathrm{pH}=6.67)$ were declined significantly ( $\mathrm{p}$ $<0.05$ ) to about 4.5 while the TA values were increased to about $0.6 \%$. Also, milks fermented with the combination of $L b$. brevis $\mathrm{B} 13$ and B38 were more acidic than those containing the single strain $(p<0.05)$. The increase in acidity could be attributed to the metabolic activity of starter and probiotic cultures, which had the ability to produce organic acids from the compounds supplied by the carob powder as polysaccharides and polyphenols. The $\mathrm{pH}$ continued to drop and TA increased throughout the whole period of cold storage to stabilize during the last week to reach 4.3 and $0.9-1.0 \%$ respectively in carob fermented milk. Several previous studies have shown that the incorporation of prebiotics may reduce the $\mathrm{pH}$ values in fermented food with advanced storage (Boudjou et al., 2014; Freire et al., 2017; Su et al., 2018). Carob powder supplementation resulted in an increase of the viscosity of the fermented milks during the storage time to reach values between 1,398 and $1,423 \mathrm{cP}$ at the end of the process. Again, the co-culture of the two probiotic strains led to more viscous milk than those fermented with the individual cultures. Our findings were in accordance with previous studies, who reported that addition of dietary fibers in fermented milk increase the viscosity of the final product (Tavares Estevam et al., 2018; Güler-Akın et al., 2016). This increase in viscosity was probably related to $\mathrm{pH}$ decrease which promotes the coagulation of milk and gel formation (Williams and Phillips, 2009). Thanks to the results obtained after the microbiological and physicochemical analyses, milk fermented with the combination of $L b$. brevis B13-B38 and fortified with $4 \%$ (w/v) of carob powder (FCP12) was further characterized as indicated below.

\subsection{Carob fermented milk during cold storage: TPC, polyphe- nolic profile and antioxidant capacity}

\subsubsection{TPC}

Figure 1a shows TPC values of the selected formulation of carob fermented milk (FCP12) determined after fermentation and at different points over the 28-days storage period. Compared to unsupplemented fermented milks (control), the incorporation of carob powder enhanced significantly the TPC in fermented milk following the fermentation to $5.48 \mathrm{mg}$ gallic acid equivalent $/ \mathrm{g}$. The

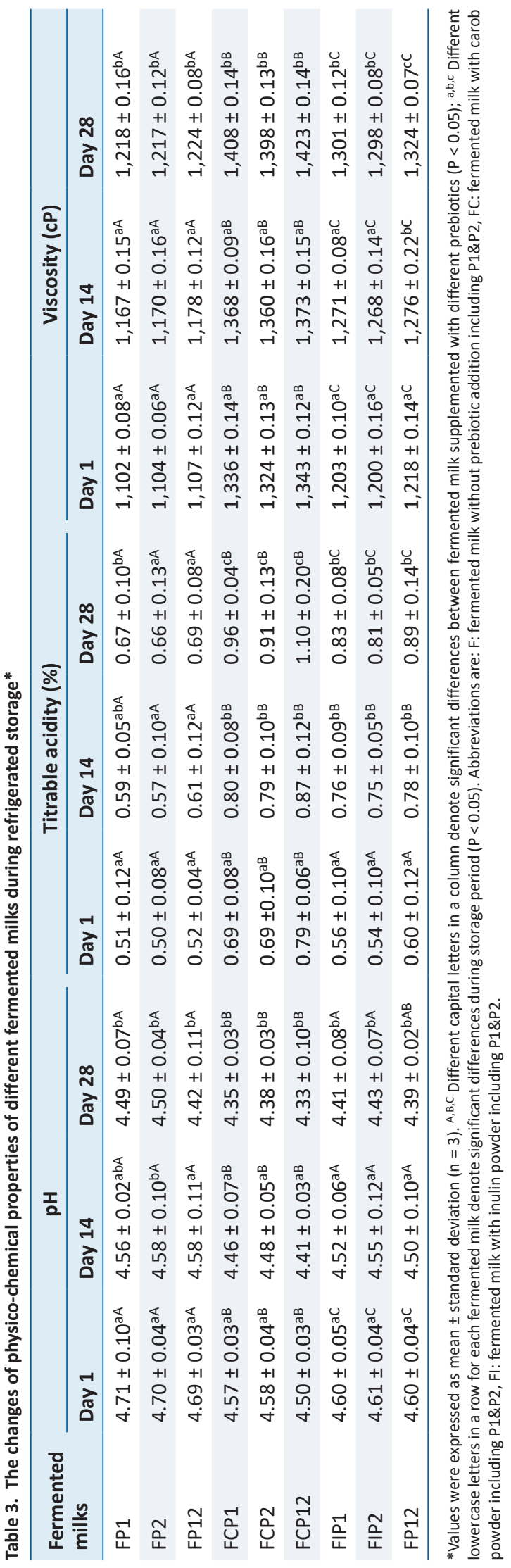



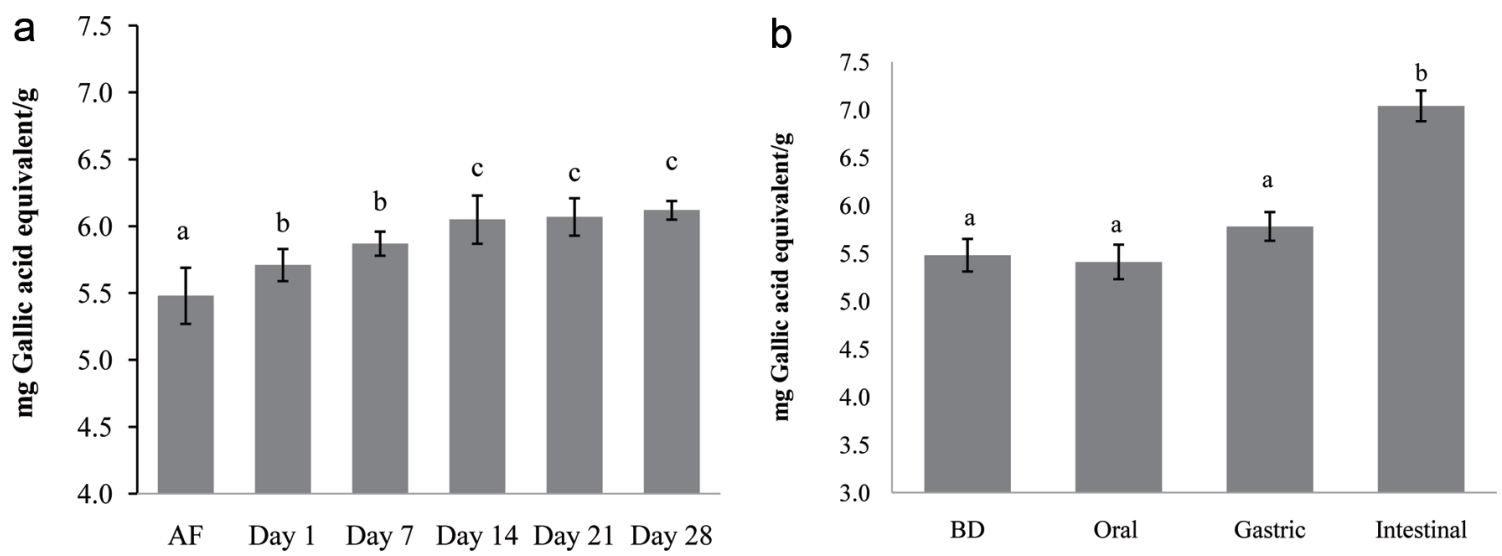

Figure 1. Changes in total phenolic content (TPC) of carob fermented milk (FCP12) during refrigerated storage (a) and in vitro digestion (b). Small letters indicate significant differences ( $<0.05)$ during storage period and different steps of digestion of the fermented milk. AF: After fermentation (16 h), BD: Before digestion.

amount of phenolic compounds in control $(1.12 \mathrm{mg}$ gallic acid equivalent/g) is probably due to the presence of other compounds in milk other than polyphenols such as low molecular weight antioxidants, free amino acids, peptides and proteins (Helal and Tagliazucchi, 2018). The TPC in the fermented milk fortified with carob increased up to D14 and then remained stable in the course of the storage time. This increase could be due to the ability of LAB strains to hydrolyze the phytochemicals complex there by releasing soluble conjugated or insoluble bounded phenolic compounds from plant cell wall (Gan et al., 2017; Kwaw et al., 2018). In addition, proteolysis of milk proteins occurring during the fermentation process may release amino acids with phenolic side chains such as tyrosine and tryptophan (Korhonen, 2009). Similarly, (Santos et al., 2017) reported an increase of TPC amount in fermented goat milk supplemented with grape pomace extract.

\subsubsection{Polyphenolic profile}

The polyphenolics compounds in carob powder and carob fermented milks (FCP12) were identified and quantified by HPLC and the results (Table 4) confirmed gallic and chlorogenic acid as the most representative phenolic acids in carob powder, whereas rutin and isoquercitrin were the most abundant flavonoids. Fermentation of the carob enriched-milk by starter and probiotic bacteria revealed interesting traits with regard to metabolization of polyphenolic compounds. As detected in carob powder, gallic acid was found at the highest concentration $(102.35 \mu \mathrm{g} / \mathrm{g})$ followed by chlorogenic acid $(33.67 \mu \mathrm{g} / \mathrm{g})$ in carob fermented milk (FCP12). Rutin and isoquercitrin were also the most quantified flavonoids. As expected, no phenolic acids and flavonoids were found in the

Table 4. Phenolic compounds of carob fermented milk (FCP12) during refrigerated storage $\left(4^{\circ} \mathrm{C}\right)^{*}$

\begin{tabular}{|c|c|c|c|c|c|}
\hline Phenolic compounds & Carob powder & Day 0 & Day 1 & Day 14 & Day 28 \\
\hline Gallic acid & $162.50 \pm 0.12$ & $102.35 \pm 0.14^{a}$ & $100.82 \pm 0.17^{a}$ & $112.41 \pm 0.07^{a}$ & $78.06 \pm 0.10^{b}$ \\
\hline Proto-catechuic acid & $39.19 \pm 0.04$ & $24.71 \pm 0.04^{a}$ & $21.20 \pm 0.08^{a}$ & $19.64 \pm 0.11^{a}$ & $10.27 \pm 0.09^{a}$ \\
\hline Chlorogenic acid & $54.12 \pm 0.11$ & $33.67 \pm 0.24^{a}$ & $34.18 \pm 0.20^{a}$ & $35.21 \pm 0.12^{a}$ & $26.14 \pm 0.07^{a}$ \\
\hline Caffeic acid & $\mathrm{Nd}$ & $\mathrm{Nd}$ & $\mathrm{Nd}$ & $\mathrm{Nd}$ & $\mathrm{Nd}$ \\
\hline p-coumaric acid & $12.77 \pm 0.11$ & $8.11 \pm 0.18^{a}$ & $8.10 \pm 0.12^{a}$ & $11.04 \pm 0.06^{a}$ & $\mathrm{Nd}$ \\
\hline Ferulic acid & $13.44 \pm 0.12$ & $7.47 \pm 0.14^{a}$ & $7.89 \pm 0.08^{a}$ & $10.41 \pm 0.07^{a}$ & $3.75 \pm 0.14^{b}$ \\
\hline o-coumaric acid & $11.07 \pm 0.04$ & $6.33 \pm 0.20^{a}$ & $5.47 \pm 0.11^{a}$ & $4.15 \pm 0.08^{a}$ & $\mathrm{Nd}$ \\
\hline Trans- cinnamic acid & $42.40 \pm 0.15$ & $24.10 \pm 0.11^{a}$ & $24.85 \pm 0.22^{a}$ & $18.47 \pm 0.07^{a}$ & $10.63 \pm 0.15^{b}$ \\
\hline Total phenolic acids (TPA) & $335.49 \pm 0.18$ & $206.74 \pm 0.14^{a}$ & $202.51 \pm 0.17^{a}$ & $211.33 \pm 0.17^{a}$ & $128.85 \pm 0.16^{b}$ \\
\hline (+)-Catechin & $11.02 \pm 0.03$ & $8.23 \pm 0.10^{a}$ & $8.21 \pm 0.11^{a}$ & $9.04 \pm 0.11^{a}$ & $\mathrm{Nd}$ \\
\hline Myricetin & $18.17 \pm 0.04$ & $10.53 \pm 0.11^{a}$ & $10.50 \pm 0.14^{a}$ & $8.12 \pm 0.15^{\mathrm{ab}}$ & $5.17 \pm 0.08^{b}$ \\
\hline Isoquercitrin & $24.47 \pm 0.06$ & $15.20 \pm 0.14^{a}$ & $15.18 \pm 0.15^{a}$ & $15.89 \pm 0.14^{a}$ & $7.57 \pm 0.11^{b}$ \\
\hline Total flavonoids (TF) & $172.02 \pm 0.14$ & $122.72 \pm 0.16^{a}$ & $122.95 \pm 0.18^{a}$ & $122.91 \pm 0.17^{a}$ & $76.81 \pm 0.11^{b}$ \\
\hline Total phenolics (TPA+TF) & $507.51 \pm 0.23$ & $329.46 \pm 0.20^{a}$ & $325.46 \pm 0.20^{a}$ & $334.24 \pm 0.20^{a}$ & $205.66 \pm 0.19^{b}$ \\
\hline
\end{tabular}

*Values are means of triplicates \pm standard deviations ( $\mu \mathrm{g} / \mathrm{g}$ of fermented milk sample). Means followed by the different letters (a,b) in the same row represent a statistically significant difference $(p<0.05)$. Nd: not detected. 

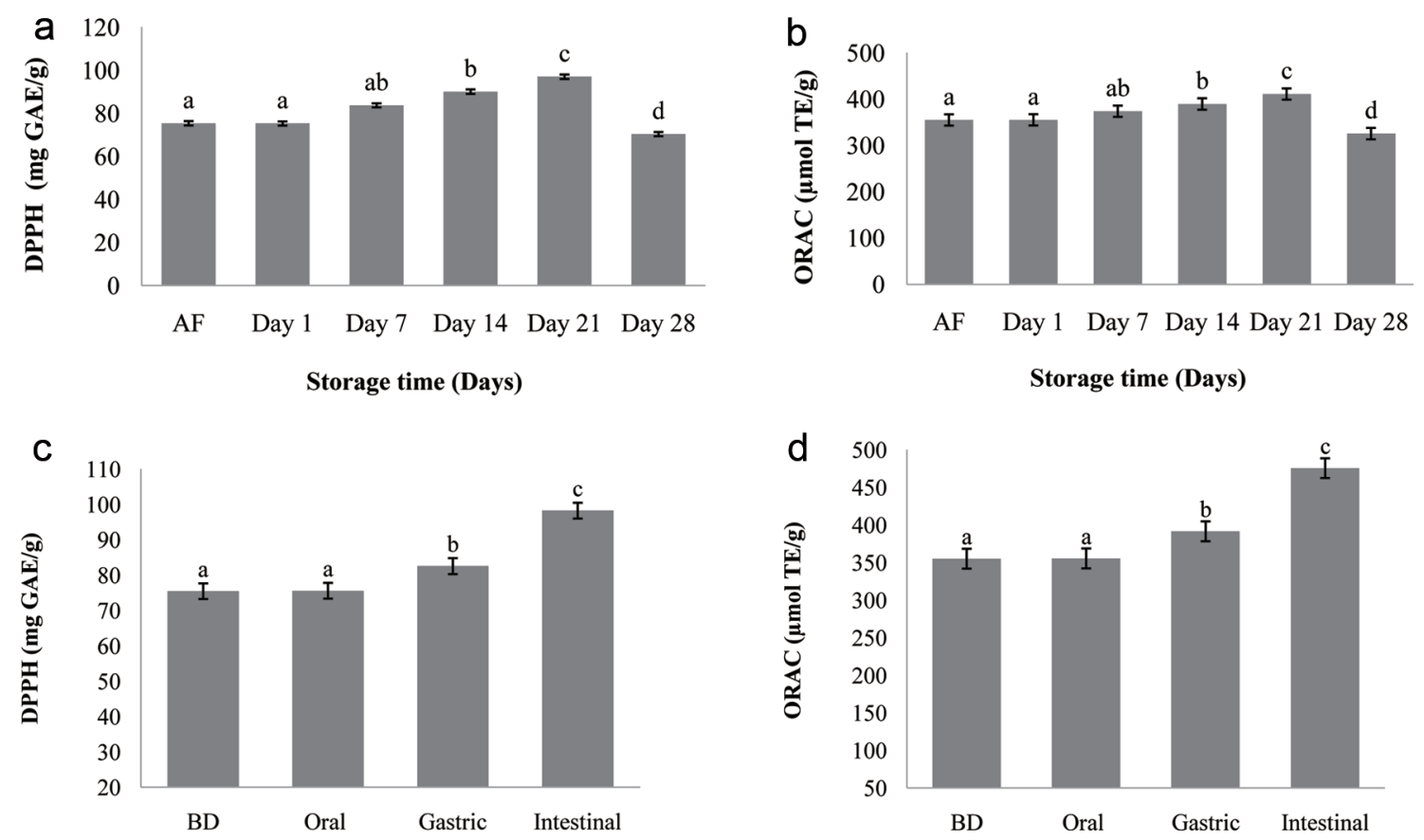

Figure 2. Antioxidant activity (DPPH and ORAC) of carob fermented milk during the refrigerated storage $\left(4^{\circ} \mathrm{C}\right)(\mathrm{a}, \mathrm{b})$ and during the in vitro digestion $(\mathrm{c}$, d). Small letters indicate significant differences $(p<0.05)$ during storage period and different steps of digestion of the fermented milk. AF: after fermentation $(16 \mathrm{~h}), \mathrm{BD}$ : before digestion.

unsupplemented fermented milk. On the contrary, proto-catechuic and ferulic acids as well as catechin behaved differently than the other phenolics and marked a significant $(\mathrm{p}<0.05)$ decrease in their concentration. The concentrations of different phenolic compounds remained constant or even slightly increased $(\mathrm{p}>0.05)$ over time refrigerated storage until D14 where the concentrations decreased significantly $(\mathrm{p}<0.05)$ to total phenolic compounds of $205.66 \mu \mathrm{g} / \mathrm{g}$ in D28. As discussed above, the changes of individual phenolics found in carob fermented milk during fermentation and cold storage are due to their metabolization by the starter and probiotic strains. The study of Curiel et al. (2010) had investigated the potential of $L b$. brevis strains to degrade food phenolic acids and reported that those strains can metabolize and decarboxylate some cinnamic acids (p-coumaric, ferulic and caffeic acids) to their corresponding vinyl derivatives (vinyl phenol, vinyl catechol, and vinyl guaiacol) via a phenolic acid decarboxylase enzyme (Curiel et al., 2010). According to the same authors, Lb. brevis can also convert gallic and protocatechuic acids to pyrogallol and catechol, respectively. Another explanation for the decrease of phenolic acids concentrations is the presence of milk proteins that can bind and precipitate carob polyphenols. Indeed, the acidic $\mathrm{pH}$ caused by the fermentation, may enhance the binding affinity between phenolic compounds and milk proteins (Helal and Tagliazucchi, 2018). Same authors found that the addition of $25 \%$ milk to a cinnamon beverage resulted in formation of insoluble complexes between cinnamon tannins and milk proteins, which decreased the total polyphenols content by $28 \%$.

\subsubsection{Antioxidant capacity}

Since the antioxidant activity of food manifests itself with different mechanisms, a single chemical method may not determine the total antioxidant capacity. For this, the antioxidant capacity of carob fermented milk (FCP12) was evaluated in the present work by two different methods. The variations in DPPH and ORAC values of carob fermented milk are shown in Figure 2a and b. The inclusion of carob powder into milk had a considerable positive effect in both DPPH and ORAC values with reference to unsupplemented milk. The mean values of DPPH and ORAC were increased ( $p<$ 0.05 ) from $75.44 \mathrm{mg} \mathrm{GAE} / \mathrm{g}$ and $355.14 \mu \mathrm{mol} \mathrm{TE} / \mathrm{g}$ respectively, in the sample after the fermentation until the $21^{\text {th }}$ day of cold storage when their level start to decrease during the last week. This result may be related to the solubilization of reducing substances in the fermented milk. High and significant positive correlation was found in carob fermented milk between TPC and both DPPH radical scavenging activity and ORAC $\left(\mathrm{R}^{2}=0.98\right.$; data not shown). This signifies that phenolic compounds are good radical scavengers. The high content of polyphenols present in carob is most certainly responsible for the antioxidant capacity exhibited in carob fermented milk. These results corroborate with the study of Munian (Muniandy et al., 2016) who reported an increase in DPPH values of yogurts supplemented with aqueous extracts of green, black and white tea (Camellia sinensis) stored for 21 days. Similarly, (Ramos et al., 2017) found that the incorporation of polyphenol-rich extract containing $87.5 \%$ cloves and $12.5 \%$ green mate increase the antioxidant activity in fermented milks.

\subsection{Carob fermented milk during the gastrointestinal diges- tion: TPC, phenolic profile and antioxidant capacity}

Gastrointestinal digestion is of major importance to assess the bioaccessibility of polyphenols and their amount released from the food matrix. Thus, in order to understand the effect of the digestion process, the fermented milk supplemented with carob (FCP12) and none supplemented one (control) were submitted to an in vitro simulation model of human digestion. 
Table 5. Phenolic compounds of carob fermented milk (FCP12) during in vitro digestion*

\begin{tabular}{|c|c|c|c|c|c|c|}
\hline Phenolic compounds & Carob powder & BF & Oral & Gastric & Intestinal & Bioaccessibility (\%) \\
\hline Gallic acid & $162.50 \pm 0.12$ & $102.35 \pm 0.14^{a}$ & $104.56 \pm 1.02^{\mathrm{a}}$ & $234.04 \pm 1.03^{b}$ & $452.12 \pm 0.99^{c}$ & 441.74 \\
\hline Proto-catechuic acid & $39.19 \pm 0.04$ & $24.71 \pm 0.04^{\mathrm{a}}$ & $24.53 \pm 1.02^{\mathrm{a}}$ & $44.76 \pm 0.99^{b}$ & $65.49 \pm 1.05^{c}$ & 265.03 \\
\hline Chlorogenic acid & $54.12 \pm 0.11$ & $33.67 \pm 0.24^{a}$ & $36.78 \pm 0.05^{a}$ & $78.23 \pm 1.02^{\mathrm{b}}$ & $102.76 \pm 0.75^{c}$ & 305.19 \\
\hline Caffeic acid & $\mathrm{Nd}$ & $\mathrm{Nd}$ & $\mathrm{Nd}$ & $\mathrm{Nd}$ & $6.45 \pm 0.08^{a}$ & $\mathrm{Nd}$ \\
\hline p-coumaric acid & $12.77 \pm 0.11$ & $8.11 \pm 0.18^{a}$ & $10.02 \pm 0.08^{a}$ & $16.06 \pm 0.45^{\mathrm{a}}$ & $21.12 \pm 0.98^{a}$ & 260.41 \\
\hline Ferulic acid & $13.44 \pm 0.12$ & $7.47 \pm 0.14^{\mathrm{a}}$ & $8.45 \pm 0.99^{a}$ & $15.17 \pm 0.87^{b}$ & $10.23 \pm 0.07^{a}$ & 136.94 \\
\hline o-coumaric acid & $11.07 \pm 0.04$ & $6.33 \pm 0.20^{\mathrm{a}}$ & $5.33 \pm 0.05^{a}$ & $\mathrm{Nd}$ & $\mathrm{Nd}$ & $\mathrm{Nd}$ \\
\hline Trans- cinnamic acid & $42.40 \pm 0.15$ & $24.10 \pm 0.11^{\mathrm{a}}$ & $26.12 \pm 0.08^{a}$ & $56.58 \pm 0.99^{b}$ & $67.44 \pm 1.05^{b}$ & 279.83 \\
\hline Total phenolic acids (TPA) & $335.46 \pm 0.21$ & $206.74 \pm 0.15^{a}$ & $215.79 \pm 0.17^{a}$ & $444.84 \pm 0.21^{b}$ & $725.61 \pm 0.24^{c}$ & $\mathrm{Nd}$ \\
\hline (+)-Catechin & $11.02 \pm 0.03$ & $8.23 \pm 0.10^{\mathrm{a}}$ & $7.49 \pm 0.08^{a}$ & $26.19 \pm 0.08^{b}$ & $40.02 \pm 1.05^{c}$ & 486.26 \\
\hline Rutin & $118.36 \pm 0.02$ & $88.76 \pm 0.15^{a}$ & $90.02 \pm 0.10^{a}$ & $128.73 \pm 0.88^{b}$ & $264.14 \pm 1.10^{c}$ & 297.58 \\
\hline Myricetin & $18.17 \pm 0.04$ & $10.53 \pm 0.11^{a}$ & $12.37 \pm 0.08^{a}$ & $28.21 \pm 0.09^{b}$ & $35.12 \pm 1.00^{b}$ & 333.52 \\
\hline Isoquercitrin & $24.47 \pm 0.06$ & $15.20 \pm 0.14^{a}$ & $16.75 \pm 0.66^{a}$ & $8.12 \pm 0.06^{b}$ & $5.36 \pm 0.09^{b}$ & 35.26 \\
\hline Total flavonoids (TF) & $172.02 \pm 0.14$ & $122.72 \pm 0.10^{a}$ & $126.63 \pm 0.11^{\mathrm{a}}$ & $191.25 \pm 0.16^{\mathrm{b}}$ & $344.64 \pm 0.14^{c}$ & $\mathrm{Nd}$ \\
\hline Total phenolics (TPA+TF) & $510.88 \pm 0.23$ & $329.46 \pm 0.17^{a}$ & $342.42 \pm 0.16^{a}$ & $636.09 \pm 0.20^{\mathrm{b}}$ & $1,070.25 \pm 0.25^{c}$ & $\mathrm{Nd}$ \\
\hline
\end{tabular}

* Results are expressed as $\mu \mathrm{g}$ of individual compound in $1 \mathrm{~g}$ of carob fermented milk. Means followed by the different letters (a,b) in the same row represent a statistically significant difference $(p<0.05)$. BF: Before digestion. Nd: not detected/determined?

\subsubsection{TPC}

Changes in TPC of carob fermented milk at different digestion stages are set out in Figure 1b. The total phenolic content presented no significant $(\mathrm{P}>0.05)$ changes in carob fermented milk during the salivary phase compared to the initial content (before digestion). After the gastric digestion, a slight increase $(p>0.05)$ in TPC was observed. A further, the intestinal step had more effect and increased significantly $(\mathrm{P}<0.05)$ the total content to $7.04 \mathrm{mg} \mathrm{GAE} / \mathrm{g}$ of fermented milk leading to a bioaccessibility of $128.47 \%$. The same trend has been previously described in stirred cinnamon-fortified yogurt in which the TPC content reached $86.7 \%$ after gastrointestinal digestion (Helal and Tagliazucchi, 2018). The increment of TPC during simulated digestion could be the result of digestive enzymes action and $\mathrm{pH}$ changes on polyphenols (conjugated and bounds) facilitating their hydrolysis and their gradual release into the digestive juice (Zhang et al., 2017). (Helal and Tagliazucchi, 2018) explained also this increase by the protective effect of the milk matrix, which bind the phenolic compounds and make them no longer available for the interaction with pepsin; and it's only when the digestion proceeds, milk proteins are hydrolysed and polyphenols can be released from milk proteins resulting in an increased of bioaccessibility.

\subsubsection{Polyphenolics profile}

Table 5 shows the evolution and the bioaccessibility of individual phenolic compounds of carob fermented milk during the in vitro digestion. At the end of the digestion process, the amount of phenolic acids and flavonoids were significantly increased $(\mathrm{P}<0.05)$ by 3 -fold compared to that before digestion. As can be observed, all the individual phenolic compounds identified in carob fermented milk were bioaccessible but showed different behavior during the digestion. The greatest bioaccessibility was marked by gallic acid (441.74\%) followed by chlorogenic acid (305.19\%). However, ferulic acid showed the highest loss with a bioaccessibility index of $136.94 \%$ after the three steps of digestion. Concerning the flavonoids content, the higher bioaccessibility was observed in (+)-catechin and myricetin with $486.26 \%$ and $333.52 \%$, respectively. Isoquercitrin was the lowest bioaccessible flavonoid (35.26\%). During the digestion, free phenolic compounds were released from the food matrix resulting in increasing their bioaccessibility index. Previous studies reported that the presence of dairy matrices significantly improved the amounts and the stability of polyphenols during the digestion, as the interaction between polyphenols and milk proteins exhibited a protective effect (Green et al., 2007).

\subsubsection{Antioxidant capacity}

Changes in the antioxidant capacity were also investigated in carob fermented milk during the digestion, and the data are depicted in Figure $2 \mathrm{c}$ and $\mathrm{d}$. Considering the changes found in TPC described above, a similar trend was observed in the antioxidant effect of carob fermented milk submitted to in vitro digestion. During the passage throughout the simulated digestion system, the DPPH and ORAC values of fortified carob fermented milk increased progressively to $98.23 \mathrm{mg} \mathrm{GAE} / \mathrm{g}$ and $475.61 \mu \mathrm{mol} \mathrm{TE} / \mathrm{g}$ respectively being $130 \%$ and $134 \%$ higher than the initial values. These results are in accordance with the data reported by (Oliveira and Pintado, 2015) for the in vitro digestion of strawberry and peach yoghurt.

\subsection{Cell viability of probiotics in carob fermented milk under the in vitro gastrointestinal simulation}

The ability to survive the digestive stresses and reach the intestine in large numbers is one of the fundamental properties of probiotics that can be successfully incorporated into food. Figure 3 illustrates the changes in cell viability of the probiotic strains in carob fer- 


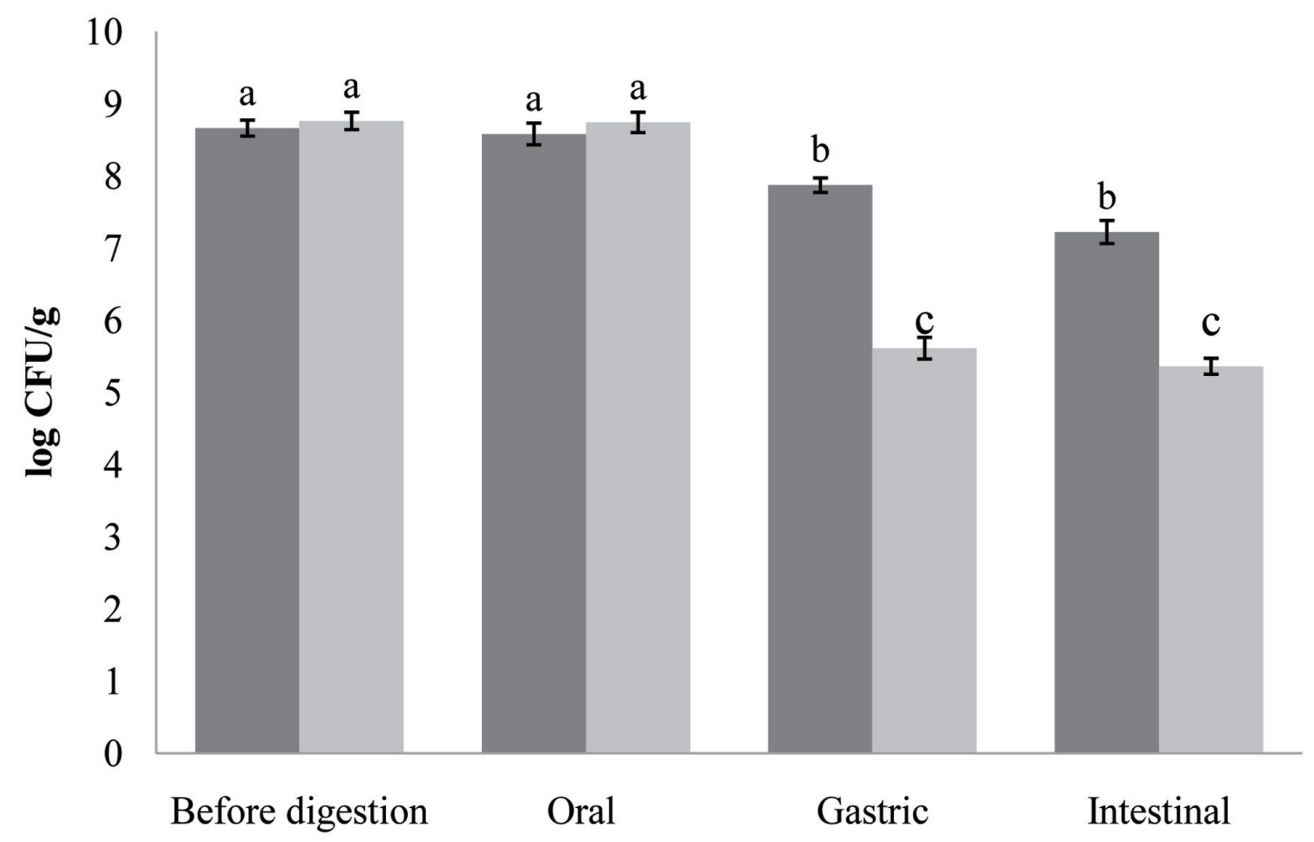

- Femented milk $\quad$ MRS broth

Figure 3. Survival of both probiotic strain ( $L b$. brevis B13 and B38) in carob fermented milk (FCP12) during the simulated gastrointestinal digestion. Small letters indicate a statistically significant difference between before the in vitro digestion counts and counts at each digestion step.

mented milk and MRS broth (control) during the gastrointestinal simulation. The gastric conditions reduced significantly $(\mathrm{p}<0.05)$ the population of the probiotic lactobacilli by $\sim 1 \log$. The effect of intestinal step was more accentuated and slowly decreased $(\mathrm{p}>$ 0.05 ) the number of lactobacilli to $7.22 \log \mathrm{CFU} / \mathrm{mL}$. This reduction in probiotic number in the fermented milk under gastrointestinal conditions was also reported by previous works (Casarotti and Penna, 2015; Moreno-Montoro et al., 2018). As expected, the lactobacilli (Lb. brevis B13 and B38) strains survived better when incorporated in carob fermented milk compared to the MRS broth. Overall, the viability of the used bacteria was maintained at an acceptable concentration and exceeded the minimum required to confer health benefits ( $6 \log \mathrm{CFU} / \mathrm{mL}$ ). The carob powder improved the lactobacilli viability and tolerance to the harsh conditions of gastrointestinal tract. In addition, the food matrix and its components may create an environment that confers protective effects to probiotic strains during the passage throughout the gastrointestinal tract. Moreover, food components could bind to bile acids, reducing their toxic effect on probiotic cells (Begley et al., 2005).

\subsection{Antibacterial activity}

The antagonist potential of probiotics could be an important prop- erty to be used as preservatives in foods, and it play a role in the regulation of the intestinal microbiota (Gharbi et al., 2018).

Results of inhibition zones presented in Table 6 Showed that control and fermented samples inhibited the growth of all pathogenic bacteria with significant differences $(p<0.05)$ between the two groups. The addition of carob powder at $4 \%$ could effectively improve the antibacterial activity of $L b$. brevis (B13, B38) strains as well as lactis C15 strain in the fermented milk. Indeed, compared with the control group, the diameter of the inhibition zone for E. coli, S. aureus, L. monocytogenes and S. typhimurium of carob fermented milk increased. In particular, the fermented milk with carob powder was more effective on $S$. aureus, indicating that the addition of carob powder presumably enhanced the antagonistic activity toward cocci. These results are in alignment with those of (Abdel-Hamid et al., 2020; Lei et al., 2021) who found that the addition of Siraitia grosvenorii and Dendrobium candidum extracts significantly enhanced the antibacterial ability of fermented milk against strains of E. coli, S. aureus and S. typhimurium.

The antagonist activity toward pathogenic bacteria could be related to the action of organic acids, bacteriocins, or other specific substances. Organic acids have a strong ability to inhibit pathogenic bacteria and are considered the important antibacterial compounds responsible for antibacterial activity of probiotics (Lei, 2011).

Table 6. Antibacterial activity in the fermented milk supplemented with $4 \%$ carob powder*

\begin{tabular}{lllc}
\hline & \multicolumn{2}{c}{ Inhibitory zone diameter } \\
\cline { 2 - 4 } & L. monocytogenes & S. aureus & S. typhimurium \\
\hline Control & $11 \pm 0.2^{\mathrm{a}}$ & $9 \pm 0.3^{\mathrm{a}}$ & $10 \pm 0.2^{\mathrm{a}}$ \\
Fermented milk (FCP12) & $12 \pm 0.4^{\mathrm{b}}$ & $14 \pm 0.2^{\mathrm{b}}$ & $11 \pm 0.1^{\mathrm{b}}$ \\
\hline
\end{tabular}

*Values are represented as mean $\pm S D(n=3)$. Means followed by the different letters $(a, b)$ in the same row indicate a statistically significant difference ( $<<0.05)$. 


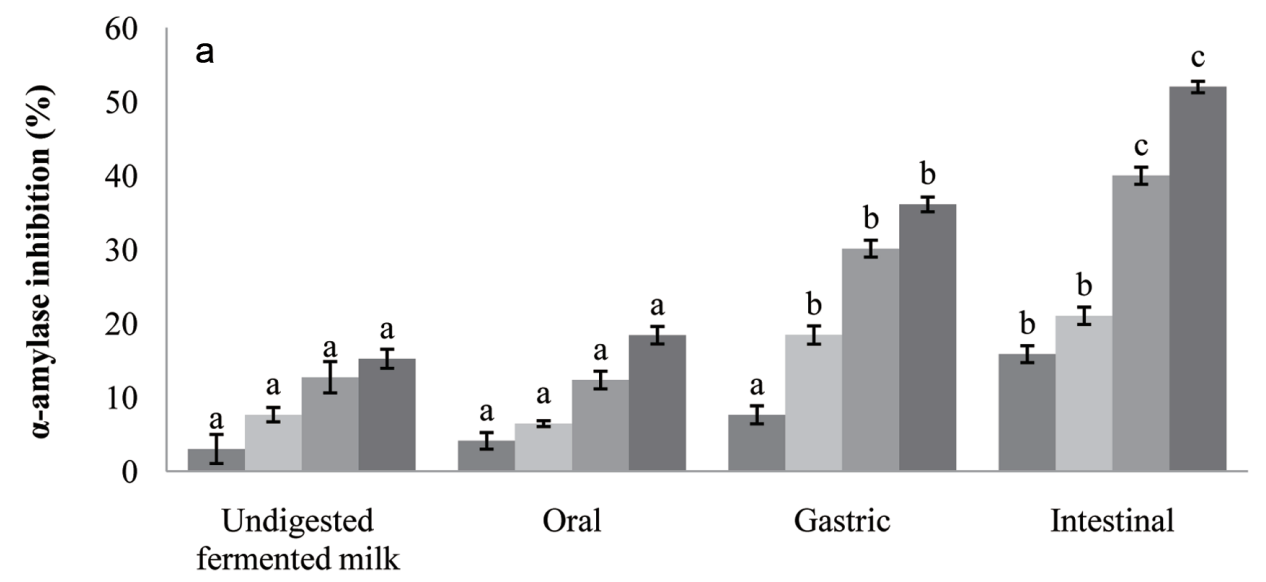

$\square 0.3 \square 0.5 \square 0.8 \square 1$

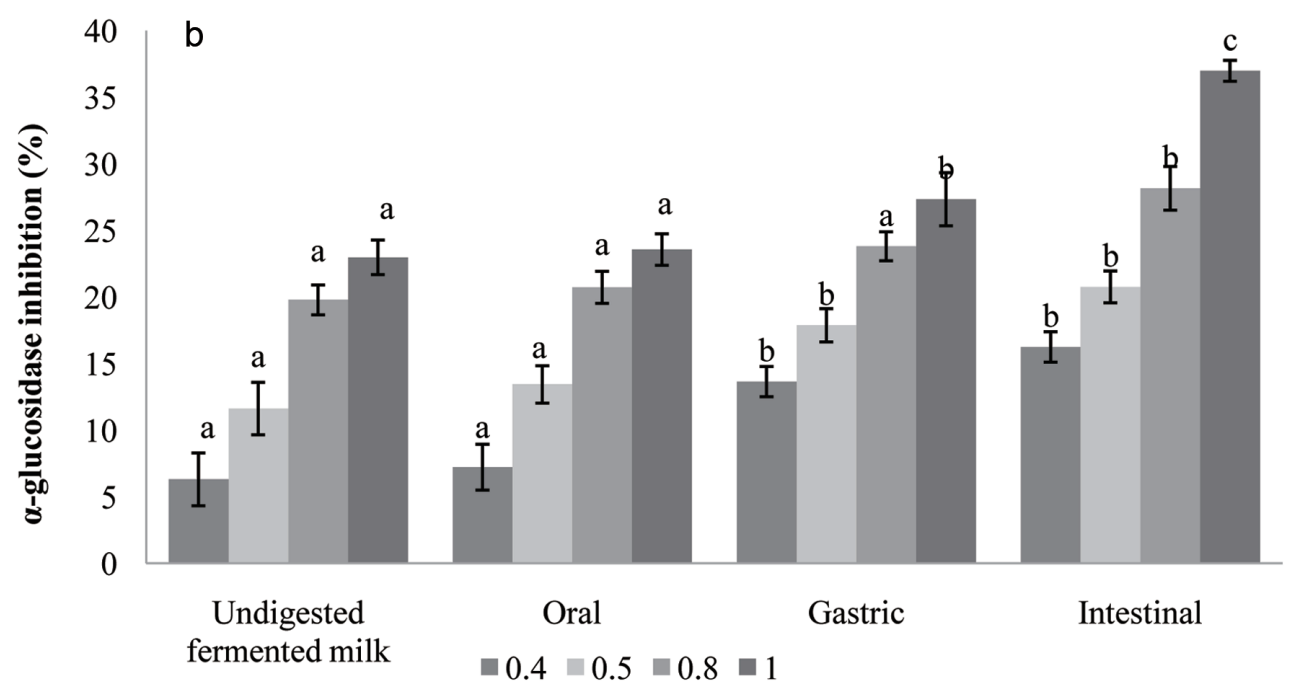

Figure 4. $\alpha$-amylase (a) and $\alpha$-glucosidase (b) inhibition (\%) of carob fermented milk (FCP12) and its digested fractions. Small letters indicate significant differences before and during digestion steps for each tested concentration $(0.3,0.4,0.5,0.8$ and $1 \mathrm{mg} / \mathrm{mL})$.

\section{7. $\alpha$-Amylase and $\alpha$-glucosidase inhibition}

In vitro simulated digestion of carob fermented milk made a significant improvement on $\alpha$-amylase and $\alpha$-glucosidase inhibitory activity Figure $4 \mathrm{a}$ and $\mathrm{b}$. It could be seen that the inhibitory effect of $\alpha$-amylase and $\alpha$-glucosidase in digested fractions was more effective than before the digestion and increased progressively $(\mathrm{P}<0.05)$ up to 3.4 and 1.6 -fold respectively. As mentioned above, the intestinal fractions exhibited high total phenolics content suggesting that the inhibition of both enzymes is dependent on polyphenolic compounds amounts. In addition, the inhibition of the $\alpha$-amylase and $\alpha$-glucosidase enzymes could be attributed also to bioactive peptides generated by the proteolytic activity of the probiotic strains (Gomes da Cruz et al., 2009). The inhibition of $\alpha$-amylase and $\alpha$-glucosidase activities can be considered as an effective approach to controlling diabetes by reducing carbohydrate metabolism (Donkor et al., 2012). The findings from this study show that the fermented milk enriched with carob powder had the potential to manage post-prandial hyperglycemia.

\section{Conclusion}

The results of the present work confirm that the addition of carob powder into fermented milk improve the probiotic (Lb. brevis B13 and B38) growth during the fermentation process and maintained their viability during the entire storage period (28 days). The carob stimulates also the acidifying activity of the used culture and increases the viscosity of fermented milk. The data showed an increment of the total phenolic content and the antioxidant capacity during storage in carob fermented milk. Carob powder has proven to be an alternative ingredient in fermented milk formulation, contributing to the development of a functional food and a synbiotic product, with high bioaccessibility polyphenols after the simulated gastrointestinal digestion, enhanced antioxidant properties, large viable numbers of probiotics and significant hypoglycemia activity. The supplementation with carob powder could be a promising type of protection agent against pathogens. Further studies need to be performed to examine the consumer sensory evaluation of the fermented milk to elucidate the most important sensory descriptors and the flavor compounds. 


\section{Acknowledgments}

The authors gratefully acknowledge financial support by the Algerian Ministry of Higher Education and Scientific Research, Laboratory of Applied Microbiology, Faculty of Natural and Life Sciences, University of Bejaia, 06000 Bejaia, Algeria. This work was also supported by Natural Sciences and Engineering Research Council of Canada -Discovery Grant (NSERC-DG, 315080).

\section{References}

Abdel-Hamid, M., Romeih, E., Huang, Z., Enomoto, T., Huang, L., and Li, L. (2019). Bioactive properties of probiotic set-yogurt supplemented with Siraitia grosvenorii fruit extract. Food Chem. 303: 125400.

Agil, R., Gaget, A., Gliwa, J., Avis, T.J., Willmore, W.G., and Hosseinian, F. (2013). Lentils enhance probiotic growth in yogurt and provide added benefit of antioxidant protection. LWT - Food Sci. Technol. 50(1): 45-49.

Ait Chait, Y., Gunenc, A., Hosseinian, F., and Bendali, F. (2021). Antipathogenic and probiotic potential of Lactobacillus brevis strains newly isolated from Algerian artisanal cheeses. Folia Microbiol. (Praha) 66(3): 429-440.

Annunziata, A., and Vecchio, R. (2013). Consumer perception of functional foods: A conjoint analysis with probiotics. Food Qual. Prefer. 28(1): 348-355.

Balthazar, C.F., Silva, H.L.A., Cavalcanti, R.N., Esmerino, E.A., Cappato, L.P., Abud, Y.K.D., Moraes, J., Andrade, M.M., Freitas, M.Q., Sant'Anna, C., Raices, R.S.L., Silva, M.C., and Cruz, A.G. (2017). Prebiotics addition in sheep milk ice cream: A rheological, microstructural and sensory study. J. Funct. Foods 35: 564-573.

Batista, A.L.D., Silva, R., Cappato, L.P., Ferreira, M.V.S., Nascimento, K.O., Schmiele, M., Esmerino, E.A., Balthazar, C.F., Silva, H.L.A., Moraes, J., Pimentel, T.C., Freitas, M.Q., Raices, R.S.L., Silva, M.C., and Cruz, A.G. (2017). Developing a synbiotic fermented milk using probiotic bacteria and organic green banana flour. J. Funct. Foods 38: 242-250.

Begley, M., Gahan, C.G.M., and Hill, C. (2005). The interaction between bacteria and bile. FEMS Microbiol. Rev. 29(4): 625-651.

Boudjou, S., Zaidi, F., Hosseinian, F., and Oomah, B.D. (2014). Effects of Faba Bean (Vicia faba L.) Flour on Viability of Probiotic Bacteria During Kefir Storage. J. Food Res. 3(6): 13-22.

Brand-Williams, W., Cuvelier, M.E., and Berset, C. (1995). Use of a free radical method to evaluate antioxidant activity. LWT - Food Sci. Technol. 28(1): 25-30.

Carlson, J.L., Erickson, J.M., Lloyd, B.B., and Slavin, J.L. (2018). Health Effects and Sources of Prebiotic Dietary Fiber. Curr. Dev. Nutr. 2(3): nzy005.

Casarotti, S.N., and Penna, A.L.B. (2015). Acidification profile, probiotic in vitro gastrointestinal tolerance and viability in fermented milk with fruit flours. Int. Dairy J. 41: 1-6.

Chait, Y.A., Gunenc, A., Bendali, F., and Hosseinian, F. (2020). Simulated gastrointestinal digestion and in vitro colonic fermentation of carob polyphenols: Bioaccessibility and bioactivity. LWT - Food Sci. Technol. 117: 108623 .

Curiel, J.A., Rodríguez, H., Landete, J.M., de las Rivas, B., and Muñoz, R. (2010). Ability of Lactobacillus brevis strains to degrade food phenolic acids. Food Chem. 120(1): 225-229.

de Souza de Azevedo, P.O., Aliakbarian, B., Casazza, A.A., LeBlanc, J.G Perego, P., and de Souza Oliveira, R.P. (2018). Production of fermented skim milk supplemented with different grape pomace extracts: Effect on viability and acidification performance of probiotic cultures. PharmaNutrition 6(2): 64-68.

de Vrese, M., and Schrezenmeir, J. (2008). Probiotics, Prebiotics, and Synbiotics. In: Stahl, U., Donalies, U.E.B., and Nevoigt, E. (Ed.). Food Biotechnology. Springer Berlin, Berlin, Heidelberg.

Donkor, O.N., Stojanovska, L., Ginn, P., Ashton, J., and Vasiljevic, T. (2012). Germinated grains - Sources of bioactive compounds. Food Chem. 135(3): 950-959.

Durazzo, A., Turfani, V., Narducci, V., Azzini, E., Maiani, G., and Carcea, M. (2014). Nutritional characterisation and bioactive components of commercial carobs flours. Food Chem. 153: 109-113.

Freire, A.L., Ramos, C.L., and Schwan, R.F. (2017). Effect of symbiotic interaction between a fructooligosaccharide and probiotic on the kinetic fermentation and chemical profile of maize blended rice beverages. Food Res. Int. 100: 698-707.

Gan, R.-Y., Shah, N.P., Wang, M.-F., Lui, W.-Y., and Corke, H. (2017). Lactobacillus plantarum WCFS1 Fermentation Differentially Affects Antioxidant Capacity and Polyphenol Content in Mung bean (Vigna radiata) and Soya Bean (Glycine max) Milks. J. Food Process. Preserv. 41(1): e12944.

Gao, L., Wang, S., Oomah, B.D., and Mazza, G. (2002). Wheat quality: Antioxidant activity of wheat millstreams. In: $\mathrm{Ng}$, P., and Wrigley, C.W. (Ed.). Wheat quality elucidation. AACC International, pp. 219-233.

Gharbi, Y., Fhoula, I., Ruas-Madiedo, P., Afef, N., Boudabous, A., Gueimonde, M., and Ouzari, H.I. (2018). In-vitro characterization of potentially probiotic Lactobacillus strains isolated from human microbiota: Interaction with pathogenic bacteria and the enteric cell line HT29. Ann. Microbiol. 69(1): 61-72.

Gibson, G.R., Hutkins, R., Sanders, M.E., Prescott, S.L., Reimer, R.A., Salminen, S.J., Scott, K., Stanton, C., Swanson, K.S., Cani, P.D., Verbeke, K., and Reid, G. (2017). Expert consensus document: The International Scientific Association for Probiotics and Prebiotics (ISAPP) consensus statement on the definition and scope of prebiotics. Nat. Rev. Gastroenterol Hepatol. 14: 491.

Gomes da Cruz, A., Alonso Buriti, F.C., Batista de Souza, C.H., Fonseca Faria, J.A., and Isay Saad, S.M. (2009). Probiotic cheese: Health benefits, technological and stability aspects. Trends Food Sci. Technol. 20(8): 344-354.

Granato, D., Santos, J.S., Salem, R.D.S., Mortazavian, A.M., Rocha, R.S., and Cruz, A.G. (2018). Effects of herbal extracts on quality traits of yogurts, cheeses, fermented milks, and ice creams: a technological perspective. Curr. Opin. Food Sci. 19: 1-7.

Green, R.J., Murphy, A.S., Schulz, B., Watkins, B.A., and Ferruzzi, M.G. (2007). Common tea formulations modulate in vitro digestive recovery of green tea catechins. Mol. Nutr. Food Res. 51(9): 1152-1162.

Guler-Akin, M., Goncu, B., and Serdar Akin, M. (2016). Some Properties of Probiotic Yoghurt Ice Cream Supplemented with Carob Extract and Whey Powder. Adv. Microbiol. 6: 1010-1020.

Gunenc, A., HadiNezhad, M., Farah, I., Hashem, A., and Hosseinian, F. (2015). Impact of supercritical CO2 and traditional solvent extraction systems on the extractability of alkylresorcinols, phenolic profile and their antioxidant activity in wheat bran. J. Funct. Foods 12: 109-119.

Hammami, R., Zouhir, A., Hamida, J.B., Neffati, M., Vergoten, G., Naghmouchi, K., and Fliss, I. (2009). Antimicrobial properties of aqueous extracts from three medicinal plants growing wild in arid regions of Tunisia. Pharm. Biol. 47: 452-457.

Helal, A., and Tagliazucchi, D. (2018). Impact of in-vitro gastro-pancreatic digestion on polyphenols and cinnamaldehyde bioaccessibility and antioxidant activity in stirred cinnamon-fortified yogurt. LWT - Food Sci. Technol. 89: 164-170.

Hill, C., Guarner, F., Reid, G., Gibson, G.R., Merenstein, D.J., Pot, B., Morelli, L., Canani, R.B., Flint, H.J., Salminen, S., Calder, P.C., and Sanders, M.E. (2014). The International Scientific Association for Probiotics and Prebiotics consensus statement on the scope and appropriate use of the term probiotic. Nat. Rev. Gastroenterol. Hepatol. 11: 506.

Huang, D., Ou, B., Hampsch-Woodill, M., Flanagan, J.A., and Prior, R.L. (2002). High-Throughput Assay of Oxygen Radical Absorbance Capacity (ORAC) Using a Multichannel Liquid Handling System Coupled with a Microplate Fluorescence Reader in 96-Well Format. J. Agric. Food Chem. 50(16): 4437-4444.

Korhonen, H. (2009). Milk-derived bioactive peptides: From science to applications. J. Funct. Foods 1(2): 177-187.

Kwaw, E., Ma, Y., Tchabo, W., Apaliya, M.T., Wu, M., Sackey, A.S., Xiao, L., and Tahir, H.E. (2018). Effect of lactobacillus strains on phenolic profile, color attributes and antioxidant activities of lactic-acid-fermented mulberry juice. Food Chem. 250: 148-154.

Lei, W., Luo, J., Wu, K., Chen, Q., Hao, L., Zhou, X., Wang, X., Liu, C., and Zhou, H. (2021). Dendrobium candidum extract on the bioactive and fermentation properties of Lactobacillus rhamnosus GG in fermented milk. Food Biosci. 41(34): 100987.

Li, L., Ding, C.C., and Li, F. (2011). Study on the antibacterial effects of two 
Dendrobium polysaccharides. Med. Plants 2(2): 21-22.

Li, S., Ma, C., Gong, G., Liu, Z., Chang, C., and Xu, Z. (2016). The impact of onion juice on milk fermentation by Lactobacillus acidophilus. LWT Food Sci. Technol. 65: 543-548.

Loullis, A., and Pinakoulaki, E. (2018). Carob as cocoa substitute: a review on composition, health benefits and food applications. Eur. Food Res. Technol. 244(6): 959-977.

Minekus, M., Alminger, M., Alvito, P., Ballance, S., Bohn, T., Bourlieu, C., Carrière, F., Boutrou, R., Corredig, M., Dupont, D., Dufour, C., Egger, L., Golding, M., Karakaya, S., Kirkhus, B., Le Feunteun, S., Lesmes, U., Macierzanka, A., Mackie, A., Marze, S., McClements, D.J., Ménard, O., Recio, I., Santos, C.N., Singh, R.P., Vegarud, G.E., Wickham, M.S.J., Weitschies, W., and Brodkorb, A. (2014). A standardised static in vitro digestion method suitable for food - an international consensus. Food Funct. 5(6): 1113-1124.

Mohanty, D., Misra, S., Mohapatra, S., and Sahu, P.S. (2018). Prebiotics and synbiotics: Recent concepts in nutrition. Food Biosci. 26: 152-160.

Moreno-Montoro, M., Navarro-Alarcón, M., Bergillos-Meca, T., GiménezMartínez, R., Sánchez-Hernández, S., and Olalla-Herrera, M. (2018). Physicochemical, Nutritional, and Organoleptic Characterization of Skimmed Goat Milk Fermented with the Probiotic Strain Lactobacillus plantarum C4. Nutrients 10(5): 633.

Muniandy, P., Shori, A.B., and Baba, A.S. (2016). Influence of green, white and black tea addition on the antioxidant activity of probiotic yogurt during refrigerated storage. Food Packag. Shelf Life 8: 1-8.

Oliveira, A., and Pintado, M. (2015). Stability of polyphenols and carotenoids in strawberry and peach yoghurt throughout in vitro gastrointestinal digestion. Food Funct. 6(5): 1611-1619.

Ortega, N., Macià, A., Romero, M.-P., Reguant, J., and Motilva, M.-J. (2011). Matrix composition effect on the digestibility of carob flour phenols by an in-vitro digestion model. Food Chem. 124(1): 65-71.

Owen, R.W., Haubner, R., Hull, W.E., Erben, G., Spiegelhalder, B., Bartsch $\mathrm{H}$., and Haber, B. (2003). Isolation and structure elucidation of the major individual polyphenols in carob fibre. Food Chem. Toxicol. 41(12) 1727-1738.
Ramos, L.R., Santos, J.S., Daguer, H., Valese, A.C., Cruz, A.G., and Granato, D. (2017). Analytical optimization of a phenolic-rich herbal extract and supplementation in fermented milk containing sweet potato pulp. Food Chem. 221: 950-958.

Dos Santos, K.M., de Oliveira, I.C., Lopes, M.A.C., Cruz, A.P.G., Buriti, F.C.A., and Cabral, L.M. (2017). Addition of grape pomace extract to probiotic fermented goat milk: the effect on phenolic content, probiotic viability and sensory acceptability. J. Sci. Food Agric. 97(4): 1108-1115.

Servili, M., Rizzello, C.G., Taticchi, A., Esposto, S., Urbani, S., Mazzacane, F. Di Maio, I., Selvaggini, R., Gobbetti, M., and Di Cagno, R. (2011). Functional milk beverage fortified with phenolic compounds extracted from olive vegetation water, and fermented with functional lactic acid bacteria. Int. J. Food Microbiol. 147(1): 45-52.

Su, N., Li, J., Ye, Z., Chen, T., and Ye, M. (2018). Quality properties, flavor and hypoglycemia activity of Kiwifruit-Bitter gourd fermented milks. Food Biosci. 22: 139-145.

Tavares Estevam, A.C., Alonso Buriti, F.C., de Oliveira, T.A., Pereira, E.V.d.S., Florentino, E.R., and Porto, A.L.F. (2018). Aqueous extract of Gracilaria birdiae (Plastino \& Oliveira) as a texture modifier in fermented milks. LWT - Food Sci. Technol. 90: 418-423.

Telagari, M., and Hullatti, K. (2015). In-vitro $\alpha$-amylase and $\alpha$-glucosidase inhibitory activity of Adiantum caudatum Linn. and Celosia argentea Linn. extracts and fractions. Indian J. Pharmacol. 47(4): 425-429.

Vasiljevic, T., and Shah, N.P. (2008). Probiotics-From Metchnikoff to bioactives. Int. Dairy J. 18(7): 714-728.

Williams, P.A., and Phillips, G.O. (2009). Introduction to food hydrocolloids. In: Phillips, G.O., and Williams, P.A. (Ed.). Handbook of Hydrocolloids (Second Edition). Woodhead Publishing, pp. 1-22.

Yao, Y., Sang, W., Zhou, M., and Ren, G. (2010). Antioxidant and $\alpha$-Glucosidase Inhibitory Activity of Colored Grains in China. J. Agric. Food Chem. 58(2): 770-774.

Zhang, B., Deng, Z., Tang, Y., Chen, P.X., Liu, R., Dan Ramdath, D., Liu, Q., Hernandez, M., and Tsao, R. (2017). Bioaccessibility, in vitro antioxidant and anti-inflammatory activities of phenolics in cooked green lentil (Lens culinaris). J. Funct. Foods 32: 248-255. 